\title{
Men in red: A reexamination of the red-attractiveness effect
}

\author{
Vera M. Hesslinger ${ }^{1,2,3}$ - Lisa Goldbach ${ }^{2,4}$. \\ Claus-Christian Carbon ${ }^{2,3,5}$
}

Published online: 17 June 2015

(C) Psychonomic Society, Inc. 2015

\begin{abstract}
Elliot, Kayser, Greitemeyer, Lichtenfeld, Gramzow, Maier, and Liu (Journal of Experimental Psychology: General, 139(3), 399-417, 2010) showed that presenting men in front of a red background or with a red shirt enhances their attractiveness, sexual desirability, and status in the eyes of female observers. The purpose of the present research was to gain further insights concerning the robustness and the ecological validity of this red effect. In two experiments, we replicated the basic paradigm used by Elliot et al. Experiment 1 was a close replication of the first experiment in their original series. We presented the photo of a young man used by Elliot et al. on either a red or white background and asked participants $(N=89$, female subsample $n=72)$ to rate it with regard to perceived attractiveness. Experiment $2(N=32)$ represents a somewhat more complex version of the first experiment; we increased the variance of the stimuli by showing photos of multiple men wearing different apparel styles (formal and casual, respectively). We did not find any significant impact of red in either of the studies. What we found, however, was a
\end{abstract}

Presented in part at the 37th European Conference on Visual Perception (ECVP), Belgrade, Serbia, August 24-28, 2014.

Vera M. Hesslinger

vera.hesslinger@uni-bamberg.de

1 Abteilung Allgemeine Experimentelle Psychologie, University of Mainz, Mainz, Germany

2 Department of General Psychology and Methodology, University of Bamberg, Markusplatz 3, D-96047 Bamberg, Germany

3 Forschungsgruppe EPÆG, Ergonomie, Psychologische Aesthetik und Gestaltung, Bamberg, Germany

4 University of Mannheim, Mannheim, Germany

5 Bamberg Graduate School of Affective and Cognitive Sciences (BaGrACS), Bamberg, Germany significant effect of apparel style with attractiveness ratings being higher for men wearing formal apparel than for men wearing casual apparel. Our results question the robustness and the ecological validity of Elliot et al.'s finding. On a more general level, they further point to limitations arising from (often necessary) restrictions in experimental designs.

Keywords Replication - Color $\cdot$ Attractiveness $\cdot$ Red effect . Status

Elliot et al. (2010) presented a series of experiments suggesting that the color red enhances male attractiveness and sexual desirability as perceived by women. They further presented evidence suggesting that this effect is mediated by an increase in perceived status. Basically, all seven experiments reported by Elliot et al. followed the same between-subjects design. Participants viewed the photo of a male target person whom they had to judge with regard to different variables, such as "perceived attractiveness," "sexual attraction," and "perceived status" (original variable labels used by Elliot et al.). The color of the background (Experiments 1-3) or the depicted man's shirt (Experiments 4-7), respectively, was manipulated as being either red or a contrasting color, e.g., white (see Table 1 for further details on the specific experiments). An enhancing effect of red was found in five of five experiments for perceived attractiveness and in three of three experiments for sexual attraction (note: in some experiments, more than one dependent variable was used). The mediation of the red effect via an increase in status could be further demonstrated in all three experiments where this variable was addressed via two different approaches: 1) the experimental-causal-chain approach, and 2) the measurement-of-mediation approach.

The accumulated results of Elliot et al. (2010) seem strikingly convincing at first sight as the authors were repeatedly 
Table 1 Overview of the seven experiments testing the red effect reported by Elliot et al. (2010)

\begin{tabular}{|c|c|c|c|c|c|}
\hline Exp. & Sample $(N /$ sex $)$ & Colors (CIE-Lch values) & $\begin{array}{l}\text { Manipulated } \\
\text { feature }\end{array}$ & Dependent measures & $\begin{array}{l}\text { Test statistics (red effect: Exp. 1-4, } \\
5 a, 6 a, 7 \text {; status effect: } 5 \text { b, } 6 \text { b }\end{array}$ \\
\hline 1 & $21 \mathrm{f}$ & $\begin{array}{l}\text { Red }(49.6,58.8,30.4) \\
\text { White (no color) }\end{array}$ & Background & Perceived attractiveness & $t(20)=2.18, d=0.95^{*}$ \\
\hline 2 & 32 f. $25 \mathrm{~m}$ & $\begin{array}{l}\text { Red }(49.6,58.8,30.4) \\
\text { White (no color) }\end{array}$ & Background & Perceived attractiveness & $\begin{array}{l}\text { Female observers: } t(53)=3.06 \text {, } \\
\quad d=1.11^{*}, \\
\text { Male observers: } n s\end{array}$ \\
\hline 3 & $33 \mathrm{f}$ & $\begin{array}{l}\text { Red }(50.0,59.6,31.3) \\
\text { Gray }(50.0,-, 69.1)\end{array}$ & Background & $\begin{array}{l}\text { Perceived attractiveness } \\
\text { Sexual attraction } \\
\text { Perceived likability }\end{array}$ & $\begin{array}{l}t(32)=2.44, d=0.86^{*} \\
t(32)=2.43, d=0.85^{*} \\
n s\end{array}$ \\
\hline 4 & $55 \mathrm{f}$ & $\begin{array}{l}\text { Red }(51.3,51.7,30.1) \\
\text { Green }(51.5,51.6,136.6)\end{array}$ & Shirt & $\begin{array}{l}\text { Perceived attractiveness } \\
\text { Sexual attraction } \\
\text { Perceived agreeableness } \\
\text { Perceived extraversion }\end{array}$ & $\begin{array}{l}t(53)=2.03, d=0.56^{*} \\
t(53)=2.25, d=0.62^{*} \\
n s \\
n s\end{array}$ \\
\hline $5 \mathrm{a}$ & $20 \mathrm{f}$ & $\begin{array}{l}\text { Red }(59.2,104.9,44.1) \\
\text { Gray }(59.3,-, 100.4)\end{array}$ & Shirt & $\begin{array}{l}\text { Perceived present status } \\
\text { Perceived status potential } \\
\text { Perceived stability }\end{array}$ & $\begin{array}{l}t(19)=2.17, d=1.11^{*} \\
t(19)=2.94, d=1.35^{* *} \\
n s\end{array}$ \\
\hline $5 b$ & $20 \mathrm{f}$ & - & Status info & $\begin{array}{l}\text { Perceived attractiveness } \\
\text { Sexual attraction }\end{array}$ & $\begin{array}{l}t(19)=4.26, d=1.96^{*} \\
t(19)=3.67, d=1.68^{* *}\end{array}$ \\
\hline $6 a$ & $37 \mathrm{f}$ & $\begin{array}{l}\text { Red }(52.3,46.3,29.0) \\
\text { Blue }(52.9,46.1,276.9)\end{array}$ & Shirt & Perceived status & $t(35)=2.23, d=0.74^{*}$ \\
\hline $6 b$ & $38 \mathrm{f}$ & - & Status info & $\begin{array}{l}\text { Perceived attractiveness } \\
\text { Sexual attraction }\end{array}$ & $\begin{array}{l}t(36)=2.82, d=0.94^{* *} \\
t(36)=2.10, d=0.70^{*}\end{array}$ \\
\hline 7 & $27 \mathrm{f}$ & $\begin{array}{l}\text { Red }(54.8,43.2,30.3) \\
\text { Blue }(55.1,43.7,283.0)\end{array}$ & Shirt & $\begin{array}{l}\text { Perceived attractiveness } \\
\text { Sexual attraction } \\
\text { Perceived status }\end{array}$ & $\begin{array}{l}\beta=0.40, F(1,25)=4.81^{*} \\
\beta=0.43, F(1,25)=6.43^{*} \\
\beta=0.42, F(1,25)=5.24^{*}\end{array}$ \\
\hline
\end{tabular}

Experiments $5 \mathrm{a} / \mathrm{b}$ and $6 \mathrm{a} / \mathrm{b}$, respectively, served to examine whether the red effect was mediated by status. To this end, an experimental-causal-chain approach was used, testing the effect of color on status (= potential mediator) in Experiment a and testing the effect of status on attractiveness/sexual attraction in Experiment b. In Experiment 7, mediation of the red effect via status was tested using a measurement-of-mediation approach whereat only the color of the target's shirt was varied between-subjects; status was not actively manipulated. For reasons of clarity, we focused on the effects of independent variables, so we only reported statistics for the red effect in Experiment 7; for results concerning the mediating role of status in Experiment 7 , see Elliot et al. (2010). ${ }^{\#}$ CIE-Lch stands for the Lightness, chroma, and hue color space established by CIE (i.e., International Commission on Illumination). Significant effects are indicated with asterisks: ${ }^{*} p<0.05, * * p<0.01$.

able to replicate their finding that a simple change in background or apparel color may have a strong and reliable impact on whether women classify a man as being attractive and sexually desirable or not. However, this flawless series of replications also turns out to be problematic as, in consideration of the estimated power of the experiments, it might indicate a publication bias in the reported, and thus accessible, results (Francis, 2013). In addition, the findings of Elliot et al. may indeed be generalizable to a certain extent (they tested participants from four countries, manipulated the color of two different features, and used four different contrasting colors); however, they lack ecological validity for a couple of reasons. First, in exclusively focusing on the impact of color, Elliot et al. neglect further important factors or features, such as apparel style (cf., for instance, Hill, Nocks, \& Gardner, 1987; McDermott \& Pettijohn II, 2011) that also may (or to a greater extent than color) affect a person's perceived attractiveness, sexual desirability, and status in real life. Second, in each of the reported experiments only one photo of a moderately attractive man was presented to the participants, and over the complete series of experiments photos of only six different male targets were used. Being thus restricted, the stimulus material does not closely reflect the variability of physical appearance found in reality. So, it is unknown whether the enhancing effect of red is restricted to a medium base level of attractiveness, and it remains unclear whether the red effect will still be found if processes of comparison that typically occur in everyday interpersonal encounters take place (e.g., different kinds of context effects, Geiselman, Haight, \& Kimata, 1984; Gerger, Leder, Faerber, \& Carbon, 2011; Kenrick \& Gutierres, 1980).

In the present research, we addressed some of the problems mentioned above and reexamined the red effect as reported by Elliot et al. (2010). We tested the robustness of the red effect and aimed to attain further insights concerning its ecological validity. We conducted two experiments replicating the basic paradigm employed by Elliot et al. to test the effect of red on perceived attractiveness and perceived status: Experiment 1 is a close replication of the first experiment in Elliot et al.'s original series with the stimulus material and the operationalization of 
the dependent measure (perceived attractiveness) being the same as used by Elliot et al. Experiment 2 represents an extended version in which we used stimuli with a wider range of variation and included apparel style as an additional factor.

\section{Experiment 1}

\section{Method}

Participants Eighty-nine students (17 males; age $M=21.9$ years, $S D=5.0$, range: $18-51$ years) voluntarily participated in the experiment that was run in the context of a psychology lecture. Participants were grouped according to the location (left-hand side, right-hand side) of their seats in the auditori$u m$. The groups were then assigned to the color conditions red ( $n 1=44,9$ male; age $M=21.2$ years, $S D=5.2$, range: $18-51$ years) and white ( $n 2=45,8$ male; age $M=22.6$ years, $S D=$ 4.8, range: $18-39$ years), respectively. Participants were naïve to the purpose of the experiment. It was ensured that participants in the condition red did not see the test material used in the condition white and vice versa.

Material We used the same grayscale photo of a moderately attractive young Caucasian man that also had been used by Elliot et al. (2010). The photo originally stems from a standard photo set established by Corneille, Monin, and Pleyers (2005). It displays the head and upper torso of a young man in a plain shirt (Fig. 1). The 4-in. $\times 6$-in. $(10.2-\mathrm{cm} \times 15.2-\mathrm{cm})$ photo was centered on an 8.5 -in. $\times 11$-in. $(21.6 \mathrm{~cm} \times 27.9 \mathrm{~cm})$ background that was either red or white. The stimuli were created using Adobe Photoshop where color can be specified by setting, e.g., CIELab values. Using an online color calculator tool (http://www. easyrgb.com/), we converted the LCh values reported by Elliot et al. for the red background (Experiment 1: $\mathrm{LCh}=49.6,58.8$, 30.4 ) to CIE-Lab values $(49.6,50.7,29.8)$. Because Photoshop only allows for inserting integers, we rounded the obtained $\mathrm{Lab}$ values $(50,51,30)$. The white background was generated by not adding any color at all, so the background was identical with the white of the paper the stimulus was printed on.

For each participant, we generated a two-page sheet printed on orthochromatic natural paper $\left(100 \mathrm{~g} / \mathrm{m}^{2}\right.$, type ColorCopy by Mondi Ltd.) with the stimulus being displayed on the first page and three questions for assessing perceived attractiveness on the second page. The questions were the same as those used by Elliot et al. but translated into German: 1) "Wie attraktiv ist diese Person Ihrer Meinung nach?" ["How attractive do you think this person is?"]; 2) "Wie angenehm ist es, diese Person anzusehen?" ["How pleasant is this person to look at?"]; and 3) "Wenn ich die gezeigte Person real träfe, würde ich denken, dass sie attraktiv ist." ["If I were to meet the person in this picture face to face, I would think he is attractive."]. The items were to be evaluated using 9-point rating scales ranging from 1 $=$ gar nicht $[$ not at all] to $9=$ sehr $[$ very much].

Procedure Depending on the condition to which they had been assigned, participants received a sheet that included the photo of the target person on a red or white background. They looked at the photo for 5 seconds, then turned it over and evaluated the displayed man's attractiveness by means of the three questions printed on the second page of the sheet.

\section{Results and discussion}

Following Elliot et al. (2010), we calculated a composite index of perceived attractiveness by averaging the scores obtained from the three test items (Cronbach's $\alpha=0.89$; for comparison, Elliot et al. obtained Cronbach's $\alpha=0.84$ ).

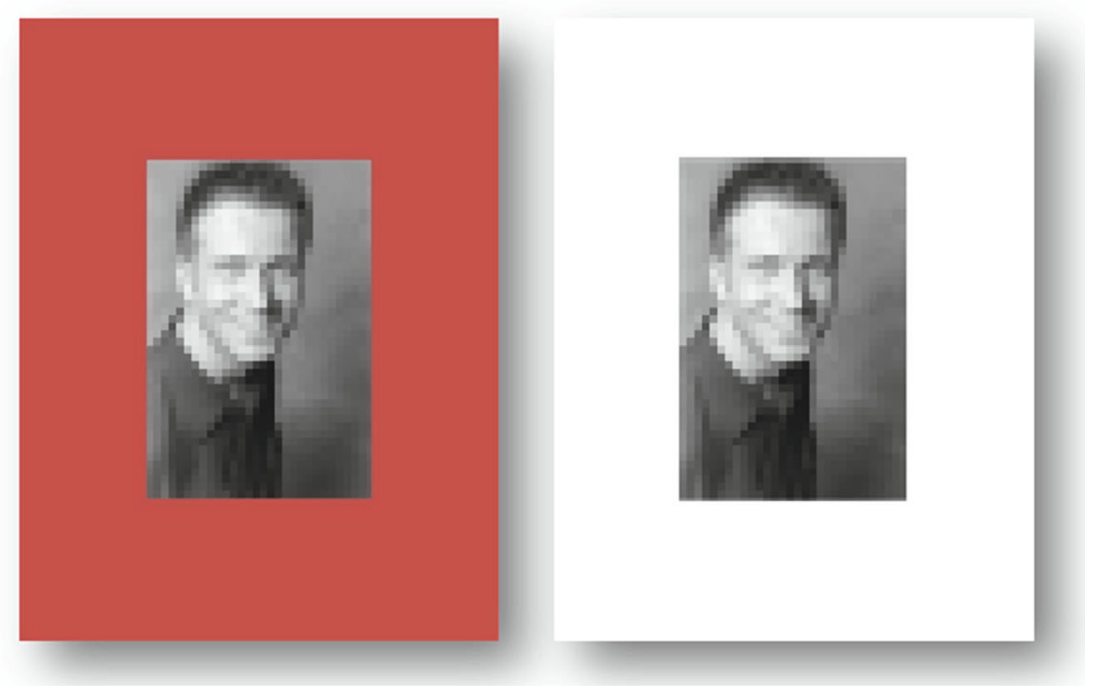

Fig. 1 The different versions of the stimulus used in Experiment 1 (left-hand side: condition red; right-hand side: condition white; depiction is scaled-down; photographs shown here are pixelated for copyright reasons) 
Participants in both color conditions gave comparable ratings of perceived attractiveness (condition red: $M=5.71, S D=$ 1.70 ; condition white: $M=5.39, S D=1.53$ ) with the small difference between the average ratings not being statistically significant, $t(87)=0.92, p=0.360, n s$. As the original study sample had exclusively comprised female participants, we reanalyzed our data split by gender. Again, there was no significant effect of color condition on perceived attractiveness, neither for the female (red: $n=35, M=5.71, S D=1.65$; white: $n=37, M=5.62, S D=1.44$ ) nor the male participants (red: $n$ $=9, M=5.70, S D=2.02$; white: $n=8, M=4.33, S D=1.59), t$ $(70)=0.24, p=0.810, n s$, and $t(15)=1.54, p=0.144, n s$, respectively. Despite having tested a larger sample of participants, we did not find an effect of red on perceived attractiveness. With a test power of 0.993 for our total sample (Fig. 2) and 0.978 for the female subsample (calculated on basis of the originally reported effect size using $\mathrm{G}^{*}$ Power 3.1.9.2 by Faul, Erdfelder, Lang, \& Buchner, 2007), the chance of missing an effect was accordingly below $0.7 \%$ and $2.2 \%$, respectively (when testing two-tailed).

\section{Experiment 2}

\section{Method}

Participants Thirty-two female students (age $M=20.2$ years, $S D=2.1$, range: $19-26$ years) voluntarily participated in the experiment for extra course credit. Half of the sample was randomly assigned to the color condition red, the other half of the sample to the color condition white. All participants had normal or corrected to normal vision (verified by a Snellen chart test) and normal color vision (verified by a short version of the Ishihara color vision test). Participants were naïve to the purpose of the experiment.

Material In order to obtain a wider range of variation in the stimulus material and to integrate the factor apparel style in Experiment 2, we utilized grayscale photos of 32 different men (Fig. 3) with 16 dressed in a suit (formal style) and 16 dressed in sportswear (casual style). The photos were taken from several online fashion catalogues. Following the scheme depicted in Fig. 4, we generated eight different sets of stimuli out of this base material. Depending on color condition, the men were shown on either a red (same red as in Experiment 1) or white (no color) background. Depending on presentation type, whole-body or torso depictions of the men were used. Whole-body depictions were approximately 5.91 in. $(15 \mathrm{~cm})$ in height; they were horizontally centered and printed on A4format paper (same paper quality as in Experiment 1). Torso depictions were cropped versions of the whole-body depictions showing the men from head to waist; they were horizontally centered and printed at the bottom line of A5-format paper.

Procedure Participants were tested individually. Each participant was assigned one of the eight sets of stimuli; assignment was counterbalanced across the sample so that four participants were tested per set. Participant and experimenter were

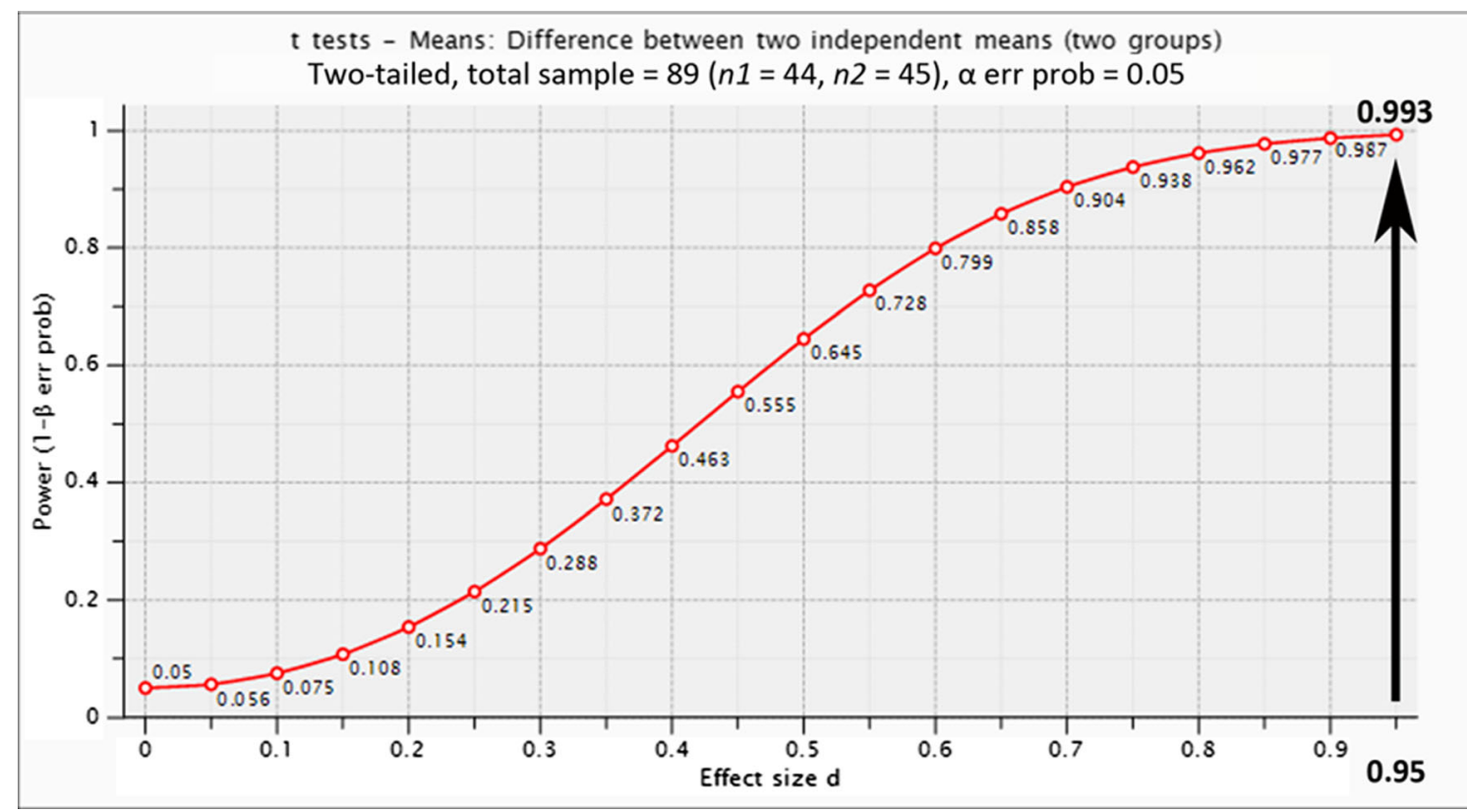

Fig. 2 Test power for Experiment $1(N=89)$ as a function of the effect size. The effect size originally reported by Elliot et al. $(2010)(d=0.95)$ and the related power obtained with our sample size are in bold print. The plot was generated using G*Power 3.1.9.2 (Faul, Erdfelder, Lang, \& Buchner, 2007) 


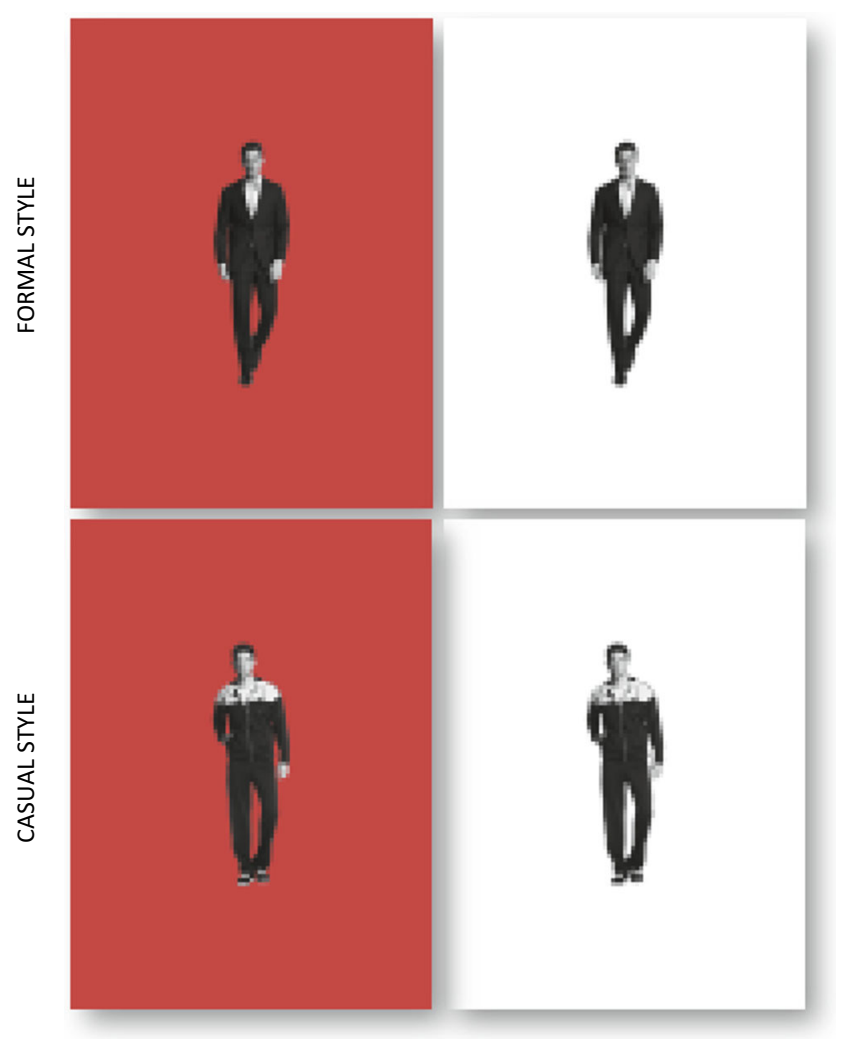

Fig. 3 Examples of the stimuli used in Experiment 2 (left-hand side: condition red; right-hand side: condition white; depictions are scaleddown; photographs shown here are pixelated for copyright reasons)

sitting next to each other, with the experimenter's view of the participant being obscured by a screen. The experimenter sequentially presented all stimuli of the picked set to the participant. After looking at a stimulus for 5 seconds, the participant evaluated the depicted man's attractiveness by means of one item ("Wie attraktiv ist die gezeigte Person?"/ "How attractive is the presented person?"), using a 9-point scale ranging from $1=$ gar nicht attraktiv [not at all attractive] to $9=$ sehr attraktiv [very attractive]. After a short break, the experimenter presented the set to the participant for a second time. Stimuli were again presented sequentially for 5 seconds each and in the same order as before. This time, the participant evaluated the status of each depicted man by means of one item ("Als wie hoch schätzen Sie den Status der Person ein?"/ "How high in status do you think this person is?"), using a 9-point rating scale ranging from $1=$ gar nicht hoch [not high at all $]$ to $9=$ sehr hoch [very high].

\section{Results and discussion}

We ran separate mixed-design analyses (ANOVA) with the within-subjects factors depiction type (whole-body, torso) and apparel style (formal, casual) and the between-subjects factor color condition (red, white) on the dependent measures perceived attractiveness and perceived status, respectively. For perceived attractiveness, we found only a significant effect of apparel style, $F(1,30)=18.9, p<0.001, \eta_{\mathrm{p}}{ }^{2}=0.387$, with men wearing formal apparel being perceived as significantly more attractive than men wearing casual apparel (Fig. 5). We detected no further significant main effects or interactions, $F \mathrm{~s}<1.8, p \mathrm{~s} \geq$ 0.193 . For perceived status, we again only found a significant effect of apparel style, $F(1,30)=237.3, p<$ $0.001, \eta_{\mathrm{p}}{ }^{2}=0.888$, with men wearing formal apparel being perceived as significantly higher in status than men wearing casual apparel (Fig. 5). There were no further significant main effects or interactions, $F_{\mathrm{s}}<2.84$, $p \mathrm{~s}$ $\geq 0$.103. So, while finding pronounced effects of apparel style in Experiment 2, we could again find no significant

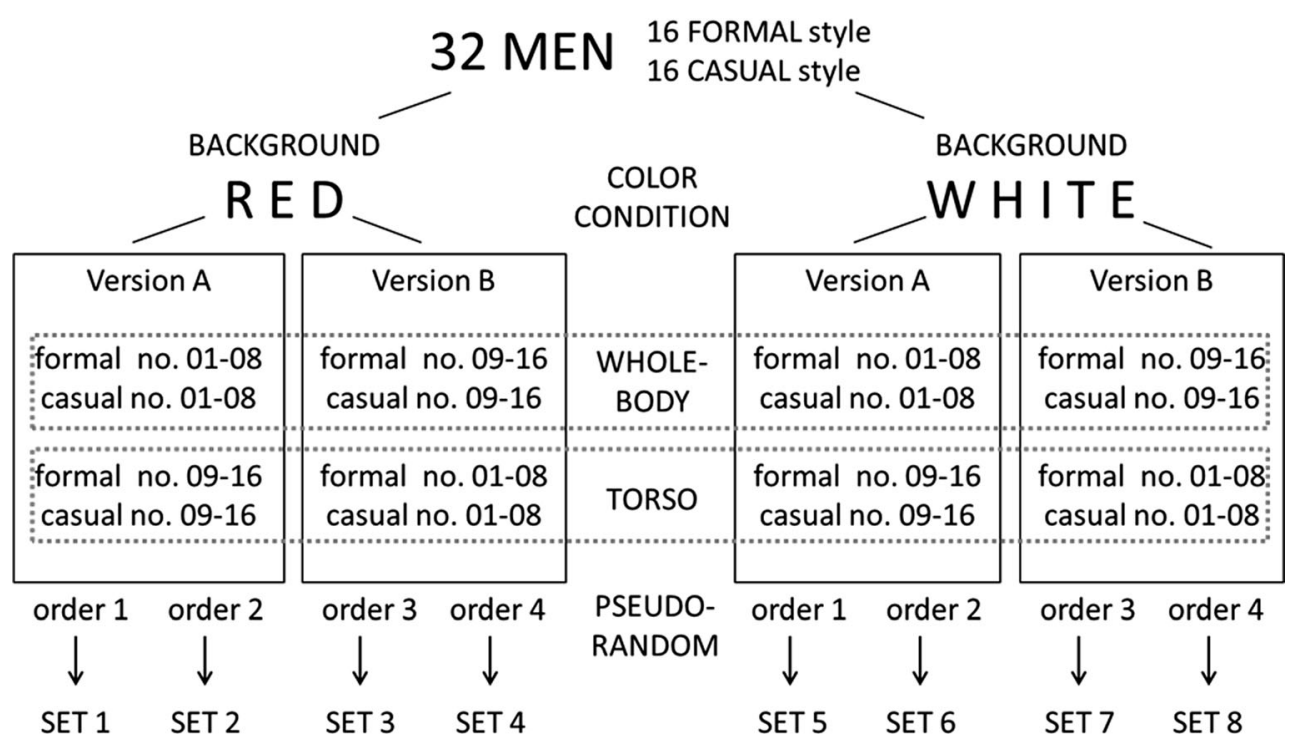

Fig. 4 Schema used for generating the different sets of stimuli used in Experiment 2 


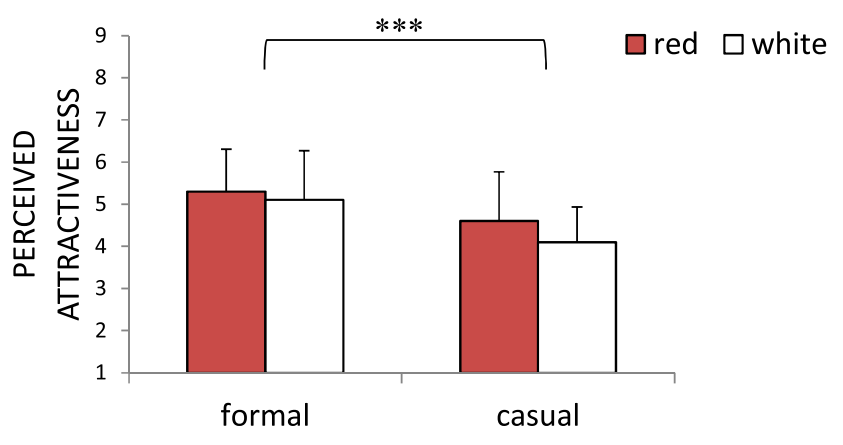

APPAREL STYLE

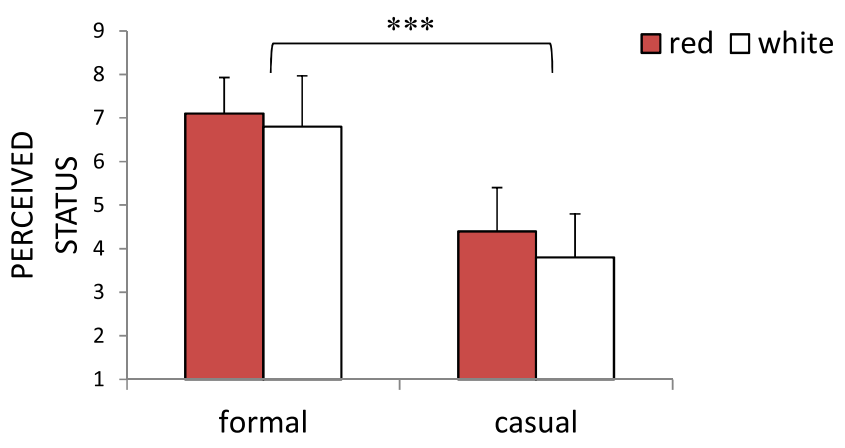

APPAREL STYLE

Fig. 5 Mean ratings of perceived attractiveness (on top) and perceived status (below), respectively, found in Experiment 2, split by the factors apparel style and color condition. Error bars indicate standard deviations. Significant effects are indicated with asterisks: ${ }^{* * *} p<0.001$

red effect as reported by Elliot et al. (2010), either on perceived attractiveness or on perceived status.

\section{General discussion}

In the present research, we reexamined the red effect as reported by Elliot et al. (2010). According to their findings, women perceive men presented in front of a red background or wearing a red shirt as being more attractive, more sexually desirable, and higher in status. We conducted two experiments replicating the basic paradigm used by Elliot et al.

Experiment 1 was a close replication of the first experiment in Elliot et al.'s (2010) original series-“close replication" in terms of: 1) having used a reproduction of the original stimulus material (same photo as used by Elliot et al., same image dimensions, also printed on paper), 2) having operationalized the dependent variable perceived attractiveness by means of the same three questions that had been asked in the original experiment, and 3) having used the same 9-point answering scale. As Brandt et al. (2014) pointed out, a replication in psychological research will never be absolutely exact or direct (see also, Stroebe \& Strack, 2014), which is, of course, also the case in the present research. Major differences compared to the original study are: 1) In contrast to Elliot et al. who tested each participant individually, we tested the whole sample at once in a group session; 2) we tested German participants instead of a sample from the United States (note, however, that Experiments 5a and 5b of Elliot et al.'s original series were conducted in Germany as well), which also required using German translations of Elliot et al.'s original questions for the assessment of perceived attractiveness; and 3 ) we utilized a larger sample size (total $N=89$, female subsample $n=72$ ), which yielded a high test power (total sample 0.993, female subsample 0.978).

Experiment 2 was an extended, thus more complex version of the original paradigm, in which we assessed the impact of red on perceived attractiveness and status using stimuli with a wider range of variation. While in Experiment 1 we used only one photo of a young man (just as had been done by Elliot et al.), we used photos of multiple men dressed in different apparel styles (formal or casual) in Experiment 2. The stimuli thus reflected at least part of the variation to be found between different persons in real life, which allowed for comparative processes common in interpersonal encounters to occur within the experimental context as well.

Neither of our replications yielded a statistically significant effect of the color red on the dependent variables (Experiment 1: perceived attractiveness, Experiment 2: perceived attractiveness and perceived status). This indicates that the red effect probably is not as robust as the multiple successful replications reported by Elliot et al. (2010) might initially suggest. Francis (2013) put forth that Elliot et al.'s results might be contaminated with publication bias. In reaction to Francis' comment, Elliot and Maier (2013) replicated the third experiment of the original series (comparing the impact of red and gray) with a larger sample $(N=144)$. This time, they did not find a significant red effect either.

Besides challenging the robustness of the red effect, our results also question its general ecological validity. We have shown that other factors may be more powerful in affecting the perception of (male) attractiveness and status than the color red: In Experiment 2, again no significant impact of red on perceived attractiveness and status occurred; both variables, however, were significantly affected by the factor apparel style: Men wearing formal suits were perceived as being more attractive than men wearing casual sportswear. Concerning perceived status, this difference was even more pronounced.

The resulting conclusion that apparel style can have an impact on how we perceive other persons is in line with findings from earlier studies (Nielsen \& Kernaleguen, 1976). Hill, Nocks, and Gardner (1987), for instance, showed that apparel displaying higher status can enhance different attractiveness measures (physical, dating, sexual, and marital attractiveness) under certain circumstances. This was especially the case for female raters evaluating male models. In Experiment 2 of the present research, the formal suits obviously conveyed a higher status than the casual sportswear as is indicated by the 
significant difference in the average ratings of perceived status that were given for men wearing these different apparel styles. According to Elliot et al. (2010), status potentially functions as a variable mediating higher perceived attractiveness. This also might be the case with regard to the impact of apparel style and perceived attractiveness that was found (status and attractiveness were significantly correlated, $r=0.576, p=0.0005$ ). Detailed and profound conclusions about such a mediation chain, however, require further experiments, and the inclusion of further potentially associated variables and constructs.

The revealed effects of apparel style with regard to perceived attractiveness and status may not have come unexpectedly and they were reasonably large $\left(\eta_{\mathrm{p}}{ }^{2}=0.387\right.$ and $\eta_{\mathrm{p}}{ }^{2}=$ 0.888 , which equals Cohen's $d=2.82$ and $d=5.63$, respectively). Yet so far this is a singular finding obtained by only one experiment in the lab, and it may well be the case that in a more naturalistic setting or in real life there are further factors having greater impact than apparel style or factors levelling its effect. Even if the effect occurs in real life, we cannot conclude that it is based on the same processes as the effect found here in the lab. Wearing formal apparel, for instance, might change the wearer's feeling and manner, which will further influence the way observers perceive him ("wearer effect"; with regard to color-associated impacts a wearer effect was shown by Roberts, Owen, \& Havlicek, 2010). Using static stimuli with an a posteriori color manipulation, as we did in the present research, does not allow for the reproduction of such processes; the effect of apparel style that we found in the lab must ipso facto be based on something else. In this regard, our experiment and its results are an exemplary case of a problem that is not too uncommon in experimental research: the potential difference between the processes taking place in an experiment with sharply specified, controlled conditions and those taking place in a markedly more complex real-life setting.

In sum, our results challenge the red effect as it was reported by Elliot et al. (2010) — which does not, however, automatically imply that red (or any other color) is principally without effect. Our conclusions are limited to the specific paradigm that was used by Elliot et al. and replicated in the present research. On a more general level, our results paradigmatically point to the consequences that arise from (necessary) restrictions in experimental designs. This does not call into question experimental psychological research per se, but it should remind us to keep in mind the scope and limitations of our findings obtained by means of the experimental approach we follow and the methods we use.

\section{References}

Brandt, M. J., IJzerman, H., Dijksterhuis, A., Farach, F. J., Geller, J., Giner-Sorolla, R., \& van 't Veer, A. (2014). The replication recipe: What makes for a convincing replication? Journal of Experimental Social Psychology, 50(1), 217-224. doi:10.1016/j.jesp.2013.10.005

Corneille, O., Monin, B., \& Pleyers, G. (2005). Is positivity a cue or a response option? Warm glow vs evaluative matching in the familiarity for attractive and not-so-attractive faces. Journal of Experimental Social Psychology, 41(4), 431-437. doi:10.1016/j. jesp.2004.08.004

Elliot, A. J., Kayser, D. N., Greitemeyer, T., Lichtenfeld, S., Gramzow, R. H., Maier, M. A., \& Liu, H. (2010). Red, rank, and romance in women viewing men. Journal of Experimental Psychology: General, 139(3), 399-417. doi:10.1037/a0019689

Elliot, A. J., \& Maier, M. A. (2013). The red-attractiveness effect, applying the Ioannidis and Trikalinos (2007b) test, and the broader scientific context: A reply to Francis (2013). Journal of Experimental Psychology: General, 142(1), 297-300. doi:10.1037/a0029592

Faul, F., Erdfelder, E., Lang, A.-G., \& Buchner, A. (2007). G*Power 3: A flexible statistical power analysis program for the social, behavioral, and biomedical sciences. Behavior Research Methods, 39(2), 175191. doi:10.3758/Bf03193146

Francis, G. (2013). Publication bias in "Red, rank, and romance in women viewing men," by Elliot et al. (2010). Journal of Experimental Psychology: General, 142(1), 292-296. doi:10.1037/a0027923

Geiselman, R. E., Haight, N. A., \& Kimata, L. G. (1984). Context effects on the perceived physical attractiveness of faces. Journal of Experimental Social Psychology, 20(5), 409-424. doi:10.1016/ 0022-1031(84)90035-0

Gerger, G., Leder, H., Faerber, S., \& Carbon, C. C. (2011). When the others matter: Context-dependent effects on changes in appreciation of innovativeness. Swiss Journal of Psychology, 70(2), 75-83. doi: 10.1024/1421-0185/a000041

Hill, E. M., Nocks, E. S., \& Gardner, L. (1987). Physical attractiveness: Manipulation by physique and status displays. Ethology and Sociobiology, 8(2), 143-154. doi:10.1016/0162-3095(87) 90037-9

Kenrick, D. T., \& Gutierres, S. E. (1980). Contrast effects and judgments of physical attractiveness: When beauty becomes a social problem. Journal of Personality and Social Psychology, 38(1), 131-140. doi: 10.1037/0022-3514.38.1.131

McDermott, L. A., \& Pettijohn, T. F., II. (2011). The influence of clothing fashion and race on the perceived socioeconomic status and person perception of college students. Psychology \& Society, 4(2), 64-75.

Nielsen, J. P., \& Kernaleguen, A. (1976). Influence of clothing and physical attractiveness in person perception. Perceptual and Motor Skills, 42(3), 775-780. doi:10.2466/pms.1976.42.3.775

Roberts, S. C., Owen, R. C., \& Havlicek, J. (2010). Distinguishing between perceiver and wearer effects in clothing color-associated attributions. Evolutionary Psychology, 8(3), 350-364.

Stroebe, W., \& Strack, F. (2014). The alleged crisis and the illusion of exact replication. Perspectives on Psychological Science, 9(1), 5971. doi: $10.1177 / 1745691613514450$ 